\title{
Effect of Air Exchange Rate on Particle Decay in a Cleanroom: A Numerical Study
}

\author{
Yunus Emre Cetin ${ }^{1, *}$, Mete Avci ${ }^{2}$, and Orhan Aydin ${ }^{2}$ \\ ${ }^{1}$ Karadeniz Technical University, Arsin Vocational School, 61900 Arsin Trabzon, Turkey \\ ${ }^{2}$ Karadeniz Technical University, Mechanical Engineering Department, 61080 Trabzon, Turkey
}

\begin{abstract}
In this study, particle decay in a cleanroom is investigated numerically. A commercial CFD package, FLUENT, is used in the analysis. The governing equations are solved by using the k- $\varepsilon$ turbulence model. For particle dispersion, the discrete phase model (DPM) is applied. Four different air change rates (3-10-25-43 ACH) with three particle diameters $(0,5-5-10 \mu \mathrm{m})$ are considered. It is shown that $10 \mathrm{ACH}$ satisfies the needs in terms of recovery time.
\end{abstract}

\section{Introduction}

Cleanroom HVAC systems are used in some industries such as semiconductor, pharmaceutical, and healthcare. They are very energy intensive, operating with large volumes of cleaned air to remove contaminants for satisfactory processes. High air flow rates also mean a great demand for heating, cooling and humidification or drying. Operating with excessive airflow rates generally depends on concerns of cleanliness reliability.

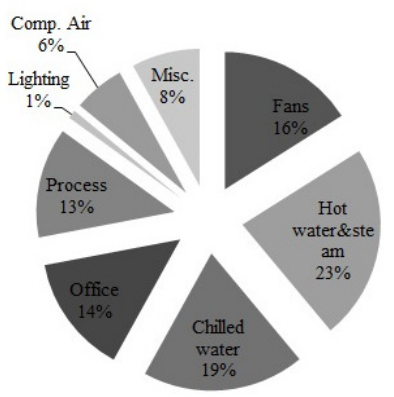

(a)

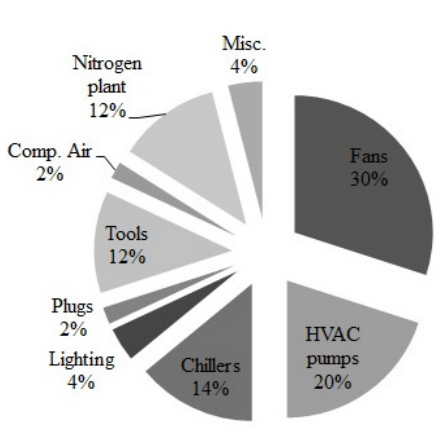

(b)

Fig. 1. Energy end-use in two cleanrooms (a)Sartor, et al. [1], (b)Tschudi, et al. [2].
Although the total energy consumption relies on different parameters, HVAC systems utilize a large percentage of it in cleanroom applications. Figure 1 shows the share of energy use of two different cleanrooms. It is seen that HVAC components have nearly $50 \%$ of total energy consumption. A reduction in fan speed can cause considerable cost savings. It is stated in BS 8568 [3] that "A 50\% reduction on flow gives an $88 \%$ reduction in power". This shows the potential of energy savings in cleanrooms.

Relation between the air flow rate and contaminant removal is important for energy efficient clean rooms. There are some studies in the literature assessing the $\mathrm{ACH}$ and contaminant decay from different aspects. Lambert et al. [4] numerically studied the contaminant decay in a controlled environment. Memarzadeh and $\mathrm{Xu}$ [5] investigated the effect of $\mathrm{ACH}$ on contaminant distribution numerically. They concluded that although increasing ventilation rate diluted concentrations, $\mathrm{ACH}$ did not increase ventilation effectiveness. Faulkner et al. [6] investigated effect of $\mathrm{ACH}$ on particle distribution in an empty ventilated room. They disclosed that concentrations did not increase linearly with an increase in actual ACH. Zhuang et al. [7] and Zhou et al. [8] studied removal of contaminants at different ventilation arrangements numerically. They showed that the particle concentration decreased faster at high air velocities.

The above literature review reveals that very limited attention has been devoted to the relation of air change rate and contaminant removal. For this purpose, detailed analyses are needed in order to understand the role of air change rate on particle decay for specific applications like cleanroom environments.

In this study, effect of air change rate on particle decay in a cleanroom is studied numerically by using a commercial software, FLUENT 16.0. Decay of

*orresponding author: yecetin@ktu.edu.tr 
randomly distributed particles at four air change rates are examined.

\section{Methods}

\subsection{Geometry}

The experimental work by Murakami et al. [9] is chosen for the current study. Murakami et al. [9] measured and simulated the velocity and concentration distribution in an isothermal turbulent mixing cleanroom. The schematic and the specifications of the cleanroom are given in Figure 2 and Table 1, respectively.

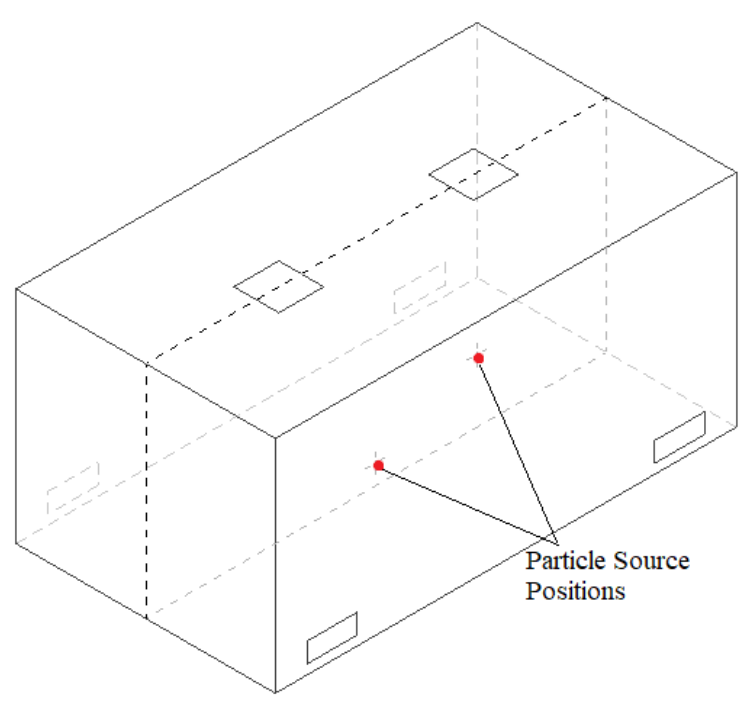

Fig. 2. The schematic of the cleanroom studied by Murakami et al. [9].

Table 1. Specifications of the cleanroom simulated.

\begin{tabular}{|c|c|c|c|}
\hline $\begin{array}{c}\text { Dimensions } \\
(\mathrm{LxWxH})(\mathrm{m})\end{array}$ & $\begin{array}{c}\text { Volume of air } \\
\text { flow }(\mathrm{m} 3 / \mathrm{s})\end{array}$ & $\mathrm{ACH}$ & $\begin{array}{c}\text { Particle size } \\
(\mu \mathrm{m})\end{array}$ \\
\hline $5.85 \times 3.29 \times 2.8$ & 0.64 & 43 & 0.31 \\
\hline
\end{tabular}

\subsection{Numerical analysis}

In this study, the SIMPLE algorithm is adapted for coupling between the pressure and velocity. The discretization scheme for the momentum is set to QUICK and the second-order upwind discretization scheme is selected for pressure, turbulent kinetic energy and turbulent dissipation rate. Convergence criterion for the equations is set to $1 \times 10^{-4}$. ICEM CFD is employed for grid generation, and grid independency test is conducted using three different structured mesh densities of $126.000,440.000$ and 1.100 .000 . Relying on insignificant changes between 440.000 and 1.100.000, a mesh density of 440.000 is selected for the current study. The boundary conditions of inlets and outlets are defined as "velocity inlet". All walls are assumed to be adiabatic and no slip boundary condition is specified. For the particulate phase, both inlets and outlets are designated as "escape", and walls are set as "trap" which means the trajectories of particles are vanished when they impact the walls.

The numerical model is validated with experimental measurements [9] as seen in Fig. 3. The results show a reasonable harmony, and the model validation is therefore considered acceptable.
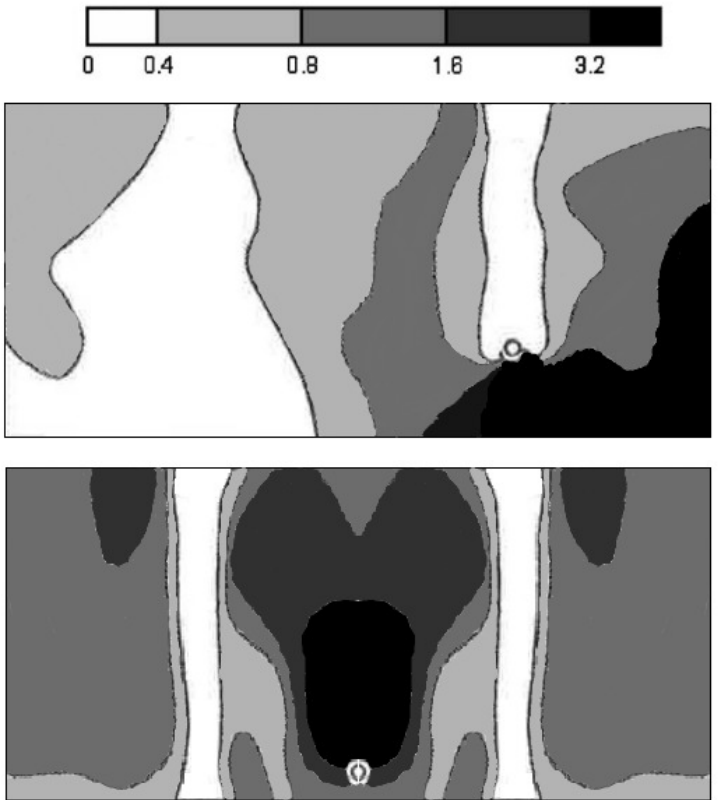

(a)
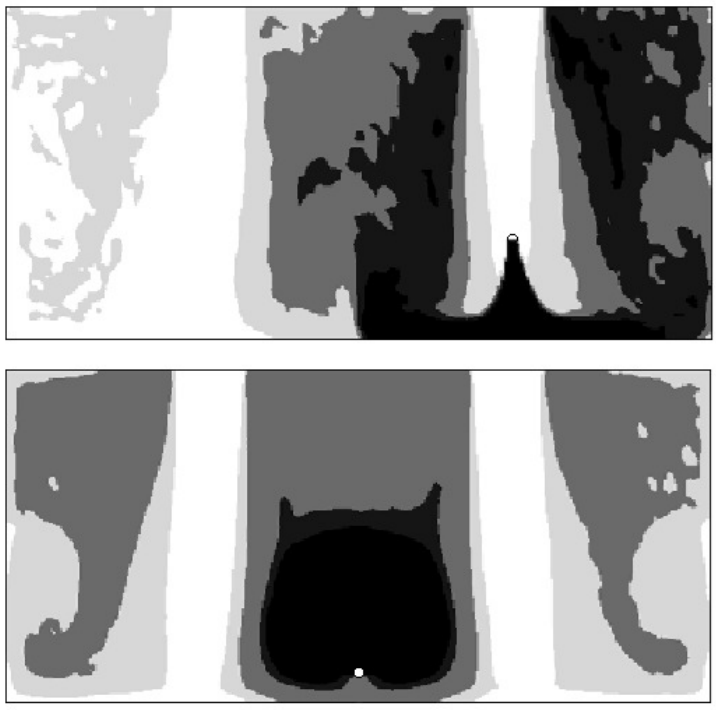

(b)

Fig. 3. Contaminant contours (a) Experimental measurements [9], (b) Simulation results. 
In the present study, three particle diameters $(0.5,5$, $10 \mu \mathrm{m})$ are examined under four different air change rates $(3,10,25$ and 43). Before the transient simulation, steady state results of airflows are obtained first. A file including starting position, initial velocity, diameter, etc. of the randomly distributed 500,000 particles is implemented as an input to DPM model. This file is generated by a custom code developed in Python. The volume averaged concentration is normalized as the initial concentration is equal to 100 .

\section{Results and Discussion}

Figure 4 shows the decay of different particle diameters at two different air change rates. It is depicted in Fig. 4a, that, at $3 \mathrm{ACH}$, the larger the diameter, the faster the particle concentration decreases. This can be explained by the effect of increasing gravitational forces with increasing the particle diameter.
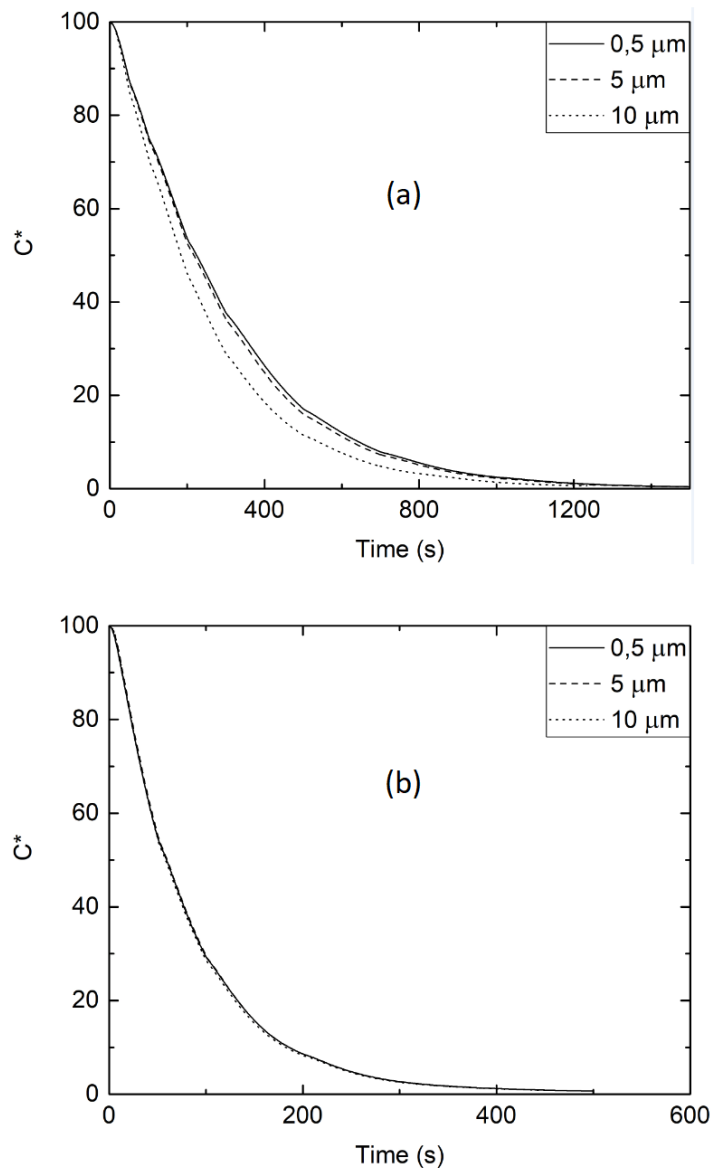

Fig. 4. Normalized concentration of three particle diameters at (a) $3 \mathrm{ACH}$, (b) $10 \mathrm{ACH}$.

As it is seen in Fig. $4 \mathrm{~b}$, the particle concentration decreases analogously at $10 \mathrm{ACH}$, independent of the particle diameter. It shows that drag forces are high enough to overcome the gravitational forces at $10 \mathrm{ACH}$.
This indicates that the particle concentration will decrease in almost the same way at higher air velocities.

Figure 5 illustrates the decay rates of specific particle diameters at different air change rates. It is clearly seen that the decrease of decay time is not in direct proportion to the increase in air change rate. The difference between $25 \mathrm{ACH}$ and $43 \mathrm{ACH}$ is nearly negligible in terms of decay time.
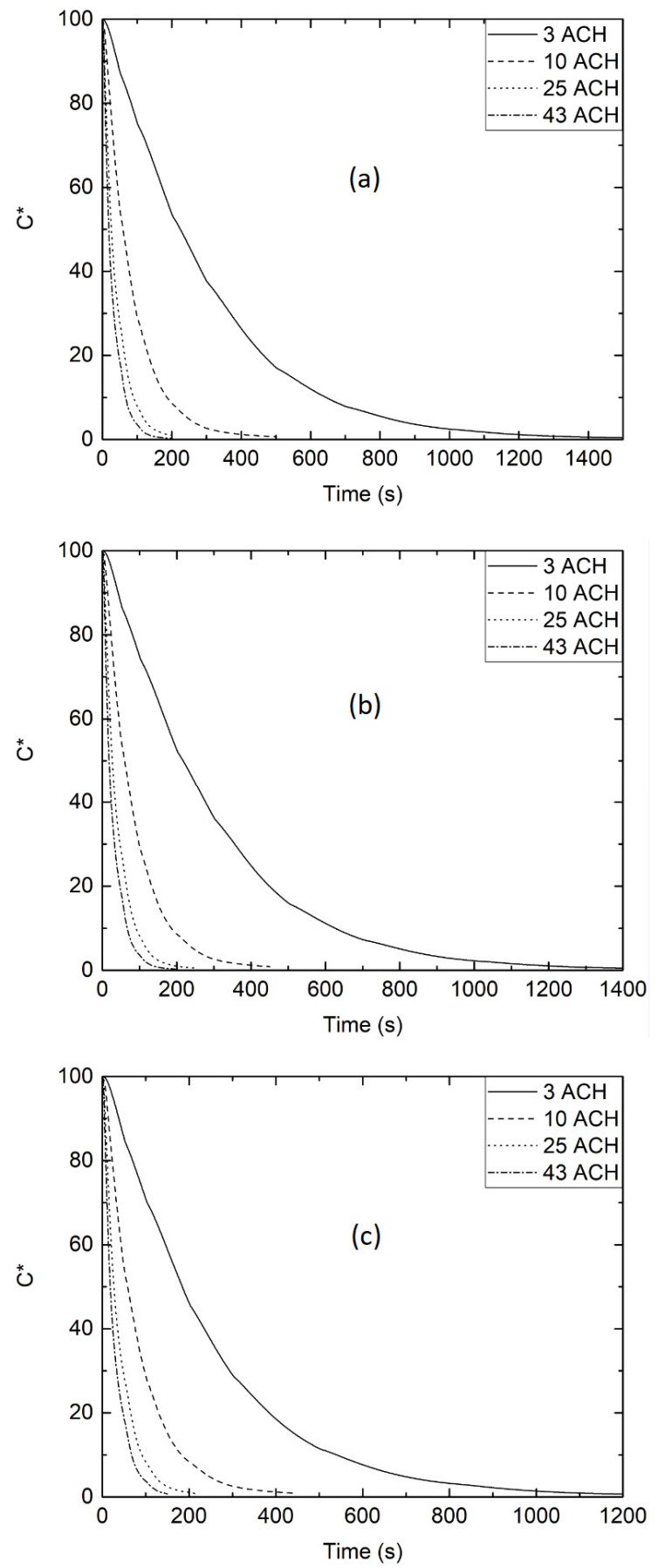

Fig. 5. Normalized concentration at different air change rates for (a) $0,5 \mu \mathrm{m}$, (b) $5 \mu \mathrm{m}$, (c) $10 \mu \mathrm{m}$. 

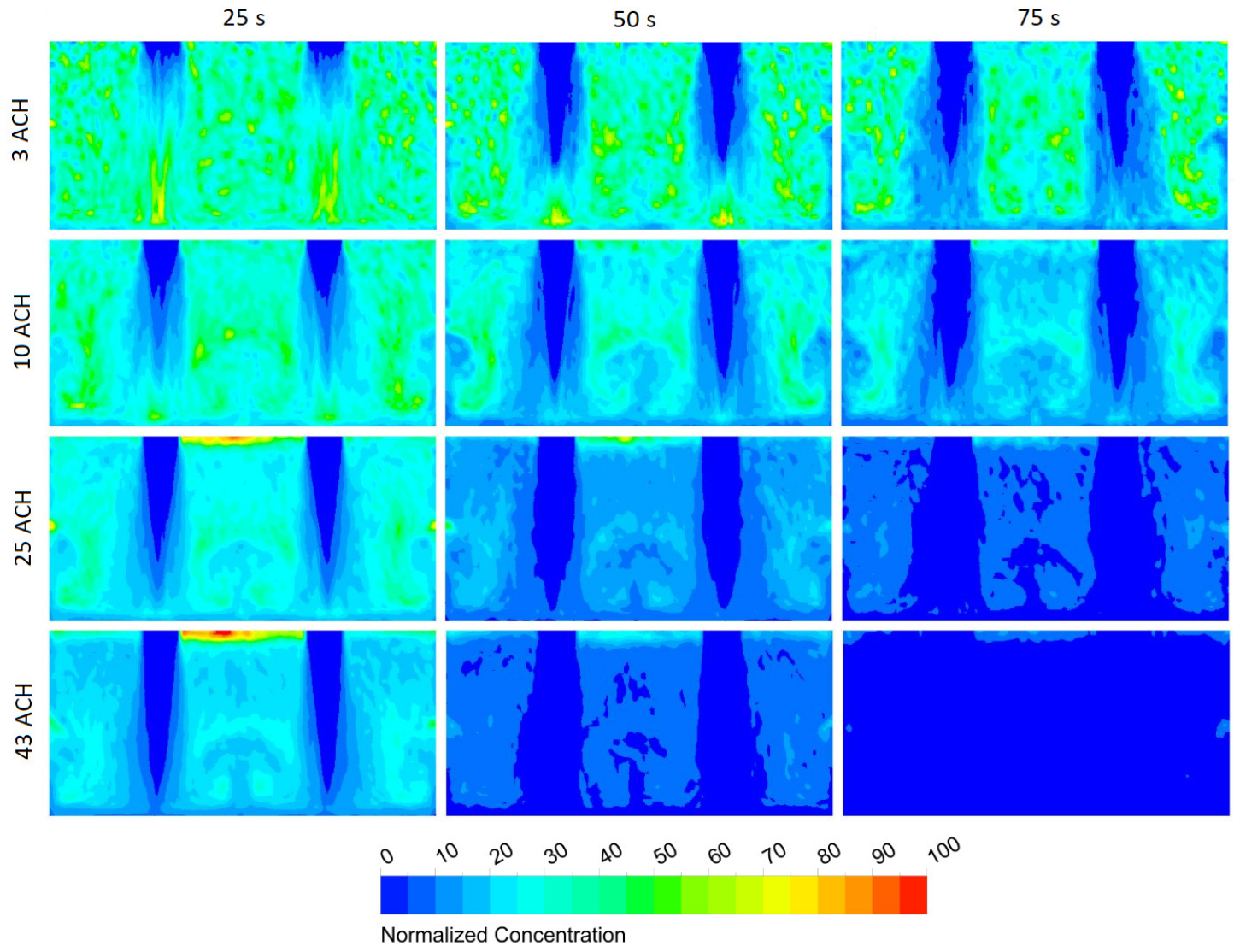

Fig. 6. Normalized concentration contours at different time frames

Concentration contours at different time frames for air change rates considered are given in Fig. 6. It is seen that the dilution starts in the jet region and then expands

For a better comparison, a quantitative analysis is performed according to the recovery test [10], which is conducted to determine the ability of ventilation systems to eliminate the contaminants in controlled environments. Recovery test is evaluated by using recovery time or the cleanliness recovery rate. Recovery time is defined as the time for the particle concentration to decrease by two order of magnitudes, and recovery rate is defined as the rate of change of particle concentration by the time. In the present study, recovery time is performed for $0.5 \mu \mathrm{m}$ particles. Desirable recovery time is in range of 15-20 minutes.

Figure 7 shows the recovery test results: $20.67 \mathrm{~min}$ for $3 \mathrm{ACH}, 7.15 \mathrm{~min}$ for $10 \mathrm{ACH}, 3.33 \mathrm{~min}$ for $25 \mathrm{ACH}$ and $2.25 \mathrm{~min}$ for $43 \mathrm{ACH}$. These values clearly indicate that the desired recovery time can be achieved by working at $10 \mathrm{ACH}$ or even at lower $\mathrm{ACH}$ values.

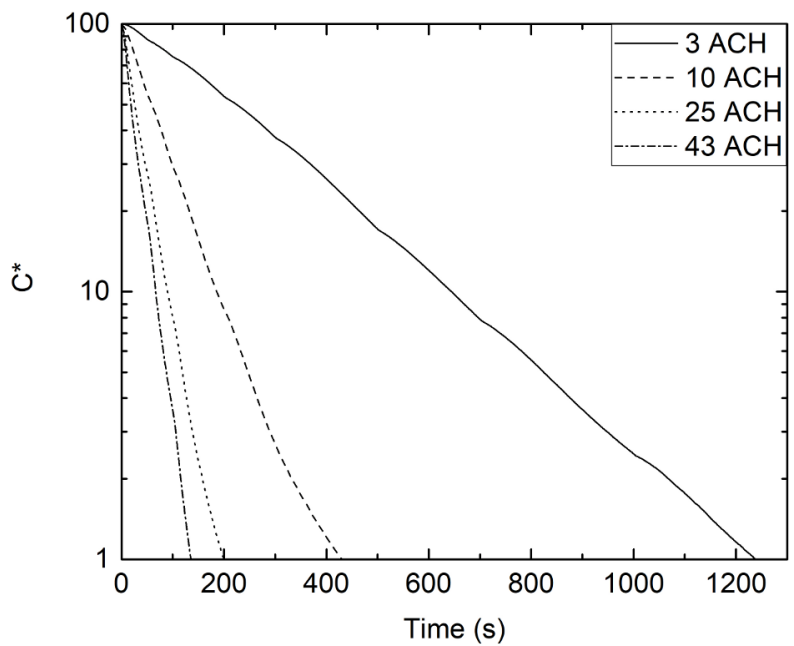

Figure 7. Recovery time at different air change rates.

\section{Conclusions}

HVAC systems in a cleanroom application have a great share in energy consumption and a possible reduction in airflow rates may cause remarkable cost savings. 
In this study, the effect of air change rates on particle decay in a conventional turbulent mixing cleanroom is investigated numerically. General findings are listed below:

- The rate of particle decay is almost the same at $\mathrm{ACH}=10$, regardless of the particle diameter.

- The increase in $\mathrm{ACH}$ and the rate of decrease of the particle concentration are not directly proportional. As ACH increases, the rate of decrease in concentration decreases.

- In terms of recovery time, $\mathrm{ACH}=10$ satisfies the desired limits which can be evaluated for possible energy savings.

\section{References}

1. D. Sartor, C. Blumstein, C. Lowell, Cleanrooms and Laboratories for High Tech Industries. California Energy Commission Final Report. (1999)

2. B. Tschudi, D. Sartor, T. Xu, An Energy Efficiency Guide for Use In Cleanroom Programming, Lawrence Berkeley National Laboratory, LBNL49223 (2001)

3. BS $8568: 2013$ Cleanroom energy - Code of practice for improving energy efficiency in cleanrooms and clean air devices.

4. A.R. Lambert, C. L. Lin, E. Mardorf, P. O'shaughnessy, Annals of occupational hygiene 54, 88 (2009)

5. F. Memarzadeh, W. Xu, Building Simulation 5, 15. (2012)

6. W. B. Faulkner, F. Memarzadeh, G. Riskowski, K. Hamilton, C.Z. Chang, J.R. Chang, Building and Environment 65, 71 (2013)

7. C. Zhuang, Y. Gang, T. Long, D. Hu, Building and Environment 112, 17 (2016)

8. Y. Zhou, Y. Deng, P. Wu, S-J. Cao, Building and Environment 125, 192 (2017)

9. S. Murakami, S. Kato, S. Nagano, S. Tanaka, ASHRAE Transactions 98, 82 (1992)

10. ISO 14644-3:2005 Cleanrooms and associated controlled environments- Part 3:Test methods. 